\title{
Outcomes in culprit only versus multivessel percutaneous coronary intervention in ST elevation myocardial infarction during index procedure
}

David Wong' ${ }^{1}$, Waqas Ahmad ${ }^{2}$, Waleed Kayani ${ }^{1}$, Ameera Ahmed ${ }^{1}$, Ihab Hamzeh ${ }^{1}$, Salim S. Virani ${ }^{1}$, Hani Jneid ${ }^{1}$, Nasser Lakkis ${ }^{1}$ and Mahboob Alam $^{1 *}$

${ }^{1}$ Baylor College of Medicine, Department of Medicine, Section of Cardiology, Houston, TX, USA

${ }^{2}$ Nishtar Medical College and Hospital, University of Health Sciences, Multan, Pakistan

\begin{abstract}
Aims: Multivessel disease seen in 40 - 65\% of STEMI patients is associated with higher mortality. ACC/AHA guidelines do not give clear indications regarding revascularization of non-infarct related arteries in the absence of cardiogenic shock while ESC/EACTS guidelines provide a class $2 \mathrm{~b}$ recommendation for multivessel $\mathrm{PCI}$ in the primary intervention in select patients. This meta-analysis aims to evaluate the role of multivessel versus culprit only percutaneous intervention (PCI) in STEMI with multivessel disease.

Methods and results: Data from 12 studies enrolling 32,548 patients was examined. Multivessel PCI was defined as PCI of culprit and non-culprit lesions during the index procedure while culprit only PCI was defined as PCI of the infarct related vessel. In-hospital all-cause mortality (OR 0.59, CI 0.36 - 0.97) and 30 day MACE (OR 0.43, CI 0.19-0.99) favored culprit vessel only PCI compared to multivessel PCI, but this did not remain significantly lower at longer follow-up. The culprit only group experienced a lower rate of stent thrombosis (OR 0.41, CI $0.21-0.78$ ). At later follow-up, multivessel PCI was associated with lower cardiac death at $12-30$ months (OR 2.58, CI 1.22 - 5.42) and lower rates of repeat revascularization at $2-2.5$ years (OR 3.77, CI 2.26, 6.27).

Conclusion: In conclusion, this meta-analysis demonstrated lower in-hospital all-cause mortality and 30-day MACE events and higher repeat revascularization with culprit only PCI. However, multi-vessel PCI during the index procedure was associated with a lower risk of cardiac death at 12-30 months. Either approach is however safe as evidenced by comparable rates of all cause death, MI, stroke, MACE events, major bleeding or vascular complications at 12 months follow-up. A significant reduction in repeat revascularization and cardiac at later follow-up was seen in patients who underwent multivessel revascularization.
\end{abstract}

\section{Introduction}

Primary percutaneous coronary intervention (p-PCI) of the culprit (infarct related) artery has become the standard of care for patients presenting with ST-elevation myocardial infarction (STEMI). Multivessel disease is seen in 40 to $65 \%$ of these patients during index angiography, and is associated with poor outcomes including higher mortality [1]. The American College of Cardiology/American Heart Association (ACC/AHA) guidelines on management of patients with STEMI are clear regarding percutaneous coronary intervention (PCI) of the culprit artery in STEMI patients with multivessel disease; however, the guidelines do not give clear indications in support of or against revascularization of non-infarct related arteries with significant stenosis at the time of p-PCI in the absence of cardiogenic shock. They acknowledge the paucity of data on the subject which makes it hard to draw robust conclusions [1]. Meanwhile, the European Society of Cardiology/ European Association for Cardio-Thoracic Surgery (ESC/ EACTS) guidelines give a class $2 \mathrm{~b}$ recommendation for multivessel PCI in the p-PCI in select patients [2,3]. Since the both guidelines were published, results from Randomized Trial of Preventive Angioplasty in Myocardial Infarction (PRAMI) and Randomized Trial of Complete Versus Lesion-Only Revascularization in Patients Undergoing Primary Percutaneous Coronary Intervention for STEMI and Multivessel Disease (CvLPRIT) trials have become available [3,4]. This metaanalysis seeks to evaluate the role of multivessel versus culprit only PCI in STEMI with multivessel disease during the index procedure.

\section{Methods}

\section{Search strategy}

A systematic search was performed to identify relevant studies in MEDLINE (PubMed), Cochrane Library, and Scopus from January 1, 2002 to March 31, 2015. Year 2002 was chosen as the initial year to focus on studies where drug eluting stents (DES) were commercially available for use. Medical Subject Heading (MeSH) keywords included were "myocardial infarction, culprit, multivessel, and PCI." Studies were limited to adult humans and excluded studies in languages other than English when translations were not available. The initial search yielded 159 citations (Scopus 75, MEDLINE 72, and Cochrane 12).

Correspondence to: Wilbert S. Aronow, MD, FACC, FAHA, Professor of Medicine, Department of Medicine, Division of Cardiology, New York Medical College, Valhalla, New York, USA, Tel: (914) 493-5311, Fax: (914)-235-6274, E-mail: wsaronow@aol.com

Key words: culprit only, multivessel, percutaneous coronary intervention, ST elevation, myocardial infarction

Received: November 01, 2016; Accepted: November 07, 2016; Published: November 10, 2016 
After reviewing titles and abstracts, 8 studies met inclusion criteria. A manual review of their references was conducted which resulted in the inclusion of 5 additional papers. However, one study was excluded because it did not provide outcomes of interest [5]. Figure 1 outlines the search methodology.

\section{Study selection}

Two reviewers (D.W. and M.A.) independently reviewed the 12 studies. The included studies reported comparative outcomes for multivessel PCI versus culprit vessel only PCI in STEMI. Studies that focused on cardiogenic shock were excluded. All included studies either excluded cardiogenic shock or reported separate outcomes. The Newcastle Ottawa Scale was used to measure the quality of nonrandomized studies. Multivessel PCI was defined as PCI of culprit and non-culprit lesions during the index procedure. Culprit only PCI was defined as PCI of the infarct related vessel during the index procedure.

We extracted baseline patient characteristics, treatment strategy, and outcome data from each included study. Primary clinical outcomes included all-cause mortality and MACE, defined as the composite end-point of death, non-fatal myocardial infarction (MI), or repeat revascularization. Secondary outcomes included cardiac death, non-fatal MI, stroke, repeat revascularization, stent thrombosis or symptomatic graft occlusion.

Endpoints such as contrast induced nephropathy and refractory angina were not evaluated due to paucity of data among the pooled studies or low number of events. Outcomes were reported at 30 days, and at 12, 24, 30 and 42 months when available. The studies' defined end-points were used for the analyses.

\section{Statistical analyses}

Percentages and means \pm SD were calculated to describe the distributions of categorical and continuous variables, respectively. Odds Ratios (OR) and their 95\% Confidence Intervals (CIs) were utilized to summarize the effect size for each clinical outcome at the corresponding time point using the random-effects model. Continuous variables were compared using the two-tailed independent samples Student's $t$ test. Categorical variables were compared using the Chi-square test with Yates' correction or Fisher's exact test, when appropriate. Measures of heterogeneity calculated include Cochran's Q-statistic, the $\mathrm{I}^{2}$ index, and the tau-squared tests. $\mathrm{I}^{2}$ greater than or equal to $25 \%$ was considered as significant heterogeneity.

Publication bias was assessed using the Funnel Plot analysis for all-cause mortality and MACE. A p value $\leq 0.05$ was considered statistically significant. Baseline data was analyzed using the Statistical Package for Social Scientists (SPSS Inc., 19.0 for Windows). The metaanalyses were performed using Review Manager (version 5.0, Cochrane Collaboration).

\section{Results}

This analysis included a total of 12 studies ( 5 RCTs, 5 retrospective cohort studies, 1 prospective observational study, and 1 case control study) enrolling 32,548 patients. Of those 32,548 patients, 27,785 underwent culprit only and 4,763 patients underwent multivessel PCI in the index procedure for STEMI. Table 1 outlines basic characteristics and follow-up of the 12 studies. The Newcastle Ottawa Scale is provided in the supplement. All studies scored at least 7/9. Weighted pooled analysis of baseline characteristics are summarized in Table 2. Baseline characteristics of patient populations included in each individual study are available in the supplement.

The incidence of diabetes mellitus, previous cerebrovascular accident (CVA), triple vessel CAD, and Left Anterior Descending (LAD) artery as culprit lesion (Table 3 ) did not vary significantly between the two groups. Patients in the culprit only PCI group were more likely to have HTN, prior MI, prior angioplasty, and prior CABG. Patients in the multivessel PCI group were more likely to be male and have history of hyperlipidemia (HLD), tobacco use, and prior CVA.

Results of our meta-analysis show that in-hospital all-cause mortality was significantly lower in patients undergoing culprit vessel only PCI compared to patients who underwent multivessel PCI (OR 0.59 , CI $0.36-0.97)$, but did not remain significantly lower at longer follow-up (30 days, 12 months, and 24 months) (Table 3, Figures $2 \mathrm{a}, 2 \mathrm{~b}$ ). Short term (defined as in-hospital or at 30 days) MACE was significantly lower for the culprit only group (OR 0.43, CI 0.19-0.99), but had comparable rates at 1 year (OR 1.00, CI 0.57 - 1.74) (Figures $3 \mathrm{a}, 3 \mathrm{~b})$. Culprit only group experienced a lower rate of stent thrombosis (OR 0.41, CI $0.21-0.78$ ), but this outcome was only reported by 2 of the 12 studies (Figure 4). Multivessel PCI was associated with lower cardiac death at 12-30 months (OR 2.58, CI 1.22 - 5.42) (Figure 5). Multivessel PCI was also associated with lower rates of repeat revascularization at 2 - 2.5 years (OR 3.77, CI 2.26, 6.27) (Figures 6a, 6b).

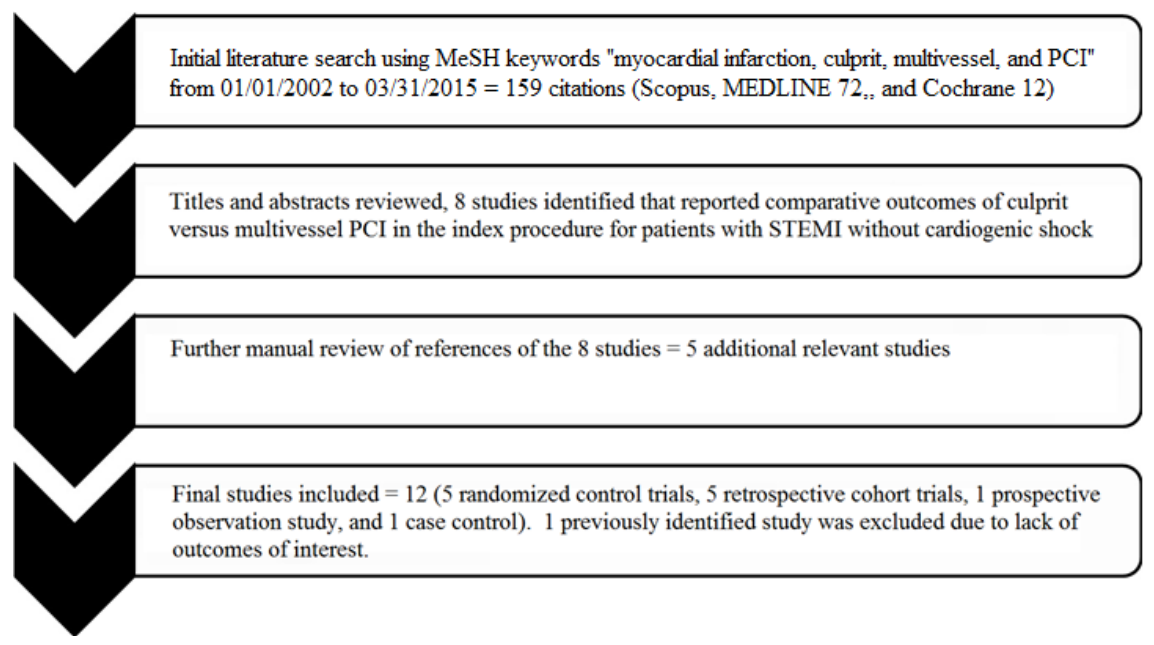

Figure 1. Literature search methodology 
Wong D (2016) Outcomes in culprit only versus multivessel percutaneous coronary intervention in ST elevation myocardial infarction during index procedure

Table 1. Summary of studies included in meta-analysis

\begin{tabular}{|c|c|c|c|c|c|c|c|}
\hline & First Author & Year & Design & Culprit only (n) & Multivessel PCI (n) & Region & $\begin{array}{l}\text { Mean follow-up } \\
\text { (months) }\end{array}$ \\
\hline 1 & Abe D & 2014 & Retrospective cohort study & 22 & 54 & Japan & $12 *$ \\
\hline 2 & Cavender MA & 2009 & Retrospective cohort study & 25809 & 3134 & USA & $0 * *$ \\
\hline 3 & Corpus RA & 2004 & Retrospective cohort study & 354 & 26 & USA & 12 \\
\hline 4 & Di Mario C. & 2004 & $\begin{array}{l}\text { Randomized controlled trial } \\
\text { (HELP AMI) }\end{array}$ & 17 & 52 & Europe & 12 \\
\hline 5 & Gerschlick AH & 2015 & $\begin{array}{l}\text { Randomized controlled trial } \\
\text { (CVLPRIT) }\end{array}$ & 146 & 150 & Europe & 12 \\
\hline 6 & HannanEL & 2010 & Case control study & 503 & 503 & USA & $22^{*}$ \\
\hline 7 & Khattab AA & 2008 & Prospective observational study & 45 & 28 & Europe & 12 \\
\hline 8 & Kornowski R & 2011 & $\begin{array}{l}\text { Randomized control trial } \\
\text { (Horizons-AMI) }\end{array}$ & 393 & 275 & $\begin{array}{l}\text { Asia, Europe, S. } \\
\text { America, USA }\end{array}$ & 12 \\
\hline 9 & Politi L & 2010 & Randomized control trial & 84 & 65 & Europe & 30 \\
\hline 10 & Qarawani D & 2008 & Retrospective cohort study & 25 & 95 & Israel & 12 \\
\hline 11 & Varani E & 2008 & Retrospective cohort study & 156 & 147 & Europe & 20 \\
\hline 12 & Wald DS & 2013 & $\begin{array}{l}\text { Randomized control trial } \\
\text { (PRAMI) }\end{array}$ & 231 & 234 & Europe & 23 \\
\hline \multicolumn{8}{|c|}{ * median follow-up } \\
\hline \multicolumn{8}{|c|}{ ** in-hospital data only } \\
\hline \multicolumn{8}{|c|}{$* * *$ post-hoc analysis } \\
\hline
\end{tabular}

Table 2. Summary of baseline characteristics.

\begin{tabular}{|l|c|c|}
\hline \multicolumn{1}{|c|}{ Culprit Only } & Multivessel & 65.3 \\
\hline Mean Age & 66.1 & $3534 / 4737(74.6 \%)$ \\
\hline Male & $20031 / 27622(72.5 \%)$ & $926 / 4036(22.9 \%)$ \\
\hline DM & $6310 / 26963(23.4 \%)$ & $2334 / 4087(57.1 \%)$ \\
\hline HLD & $16929 / 26963(62.8 \%)$ & $2026 / 3788(53.5 \%)$ \\
\hline Tobacco Use & $12483 / 26648(46.8 \%)$ & $2452 / 4022(61 \%)$ \\
\hline Prior MI & $13286 / 26879(49.4 \%)$ & 0.003 \\
\hline Prior CABG & $5066 / 26817(18.9 \%)$ & 0.5334 \\
\hline Prior CVA & $2571 / 26457(9.7 \%)$ & $193 / 3610(5.3 \%)$ \\
\hline Prior angioplasty & $2032 / 26756(7.6 \%)$ & $294 / 3925(7.5 \%)$ \\
\hline 3v Dz & $4529 / 26366(17.2 \%)$ & 0.0001 \\
\hline LAD culprit & $430 / 1427(30.1 \%)$ & 0.0001 \\
\hline
\end{tabular}

Table 3. Clinical outcomes in patients undergoing culprit only or multivessel PCI for STEMI.

\begin{tabular}{|c|c|c|c|c|c|c|c|c|c|c|c|c|}
\hline \multirow[t]{2}{*}{ Outcome } & \multirow[t]{2}{*}{ Follow-up } & \multirow[t]{2}{*}{ Studies } & \multirow[t]{2}{*}{ Patients } & \multicolumn{2}{|c|}{ Event Rate Culprit Only } & \multicolumn{2}{|c|}{ Event Rate Multivessel } & \multirow[t]{2}{*}{ Odds Ratio (Random) } & \multirow[t]{2}{*}{$\mathbf{Q}^{(\star)}$} & \multirow[t]{2}{*}{$\mathbf{P}^{(\#)}$} & \multirow[t]{2}{*}{$\mathbf{I}^{2(\S)}$} & \multirow[t]{2}{*}{$\tau^{2(\|)}$} \\
\hline & & & & $\mathrm{N} /$ total & $\%$ & $\mathrm{~N} /$ total & $\%$ & & & & & \\
\hline \multirow[t]{5}{*}{ All-Cause Death } & In-hospital & 8 & 31237 & $642 / 27161$ & 2.36 & $136 / 4076$ & 3.34 & $0.59\left(\begin{array}{llll}0.36 & -0 & 0.97)\end{array}\right.$ & 14.52 & 0.04 & 52 & 0.21 \\
\hline & 30 - days & 2 & 453 & $25 / 399$ & 6.27 & 19876 & 11.11 & $0.41(0.15-1.10)$ & 1.19 & 0.28 & 16 & \\
\hline & 12 - months & 8 & 2886 & $118 / 1703$ & 6.93 & $99 / 1183$ & 8.37 & $0.60(033-1.07)$ & 17.79 & 0.01 & 61 & 0.37 \\
\hline & 24 - months & 2 & 1471 & $92 / 737$ & 12.48 & $72 / 737$ & 9.77 & $1.35(0.43-4.25)$ & 11.45 & 0.0007 & 91 & 0.63 \\
\hline & $24-42$ - months & 3 & 1620 & $126 / 818$ & 15.40 & $94 / 802$ & 11.72 & $1.53(0.74-3.20)$ & 9.82 & 0.007 & 80 & 0.32 \\
\hline \multirow[t]{2}{*}{ MACE ${ }^{(*)}$} & $\begin{array}{l}\text { Short term (30-day } \\
\text { or in-Hospital) }\end{array}$ & 3 & 67 & $56 / 416$ & 13.46 & $11 / 97$ & 11.34 & $0.43(0.19-0.99)$ & 1.02 & 0.6 & 0 & 0 \\
\hline & $12-$ months & 5 & 1486 & $200 / 955$ & 20.94 & $91 / 531$ & 17.14 & $1.20(0.66-2.18)$ & 11.7 & 0.02 & 66 & 0.28 \\
\hline \multirow[t]{2}{*}{ Myocardial infarction } & In-hospital & 3 & 569 & $14 / 396$ & 3.54 & $4 / 173$ & 2.31 & $2.32(0.30-17.73)$ & 2.44 & 0.12 & 59 & 1.29 \\
\hline & 12 - months & 6 & 1760 & $47 / 1175$ & 4.00 & $28 / 585$ & 4.79 & $0.82(0.50-1.36)$ & 3.41 & 0.64 & 0 & 0 \\
\hline \multirow[t]{2}{*}{ Non-fatal Stroke } & $\begin{array}{l}\text { Short term (30-day } \\
\text { or in-Hospital) }\end{array}$ & 3 & 29389 & $110 / 26201$ & 0.42 & $13 / 3188$ & 0.41 & $1.02(0.58-1.81)$ & 0.34 & 0.84 & 0 & 0 \\
\hline & 12 - months & 3 & 1238 & $10 / 759$ & 1.32 & $4 / 479$ & 0.84 & $1.34(0.39-4.59)$ & 0.23 & 0.89 & 0 & 0 \\
\hline \multirow{2}{*}{$\begin{array}{l}\text { Target Vessel } \\
\text { Revascularization }\end{array}$} & 30 - days & 2 & 453 & $30 / 399$ & 7.52 & 19784 & 5.56 & $1.12(0.27-4.76)$ & 0.77 & 0.38 & 0 & 0 \\
\hline & 12-month & 5 & 1691 & $141 / 1158$ & 12.18 & $47 / 533$ & 8.82 & $1.18(0.81-1.71)$ & 2.68 & 0.61 & 0 & 0 \\
\hline \multirow{2}{*}{$\begin{array}{l}\text { Repeat } \\
\text { Revascularization }\end{array}$} & In-hospital & 3 & 262 & $20 / 87$ & 22.99 & $14 / 175$ & 8.00 & $2.48(0.76-8.14)$ & 3.75 & 0.15 & 47 & 0.5 \\
\hline & $2-2.5$ years & 2 & 614 & $74 / 315$ & 23.49 & $22 / 299$ & 7.36 & $3.77(2.26-6.27)$ & 0.42 & 0.52 & 0 & 0 \\
\hline Cardiac Death & $12-30$ - months & 3 & 910 & $27 / 461$ & 5.86 & $10 / 449$ & 2.23 & $2.58(1.22-5.42)$ & 0.34 & 0.84 & 0 & 0 \\
\hline Stent thrombosis & 12 - months & 2 & 942 & $21 / 613$ & 3.43 & $22 / 329$ & 6.69 & $0.41(0.21-0.78)$ & 0.08 & 0.77 & 0 & 0 \\
\hline Major Bleeding & 12 - months & 3 & 1344 & $60 / 893$ & 6.72 & $31 / 451$ & 6.87 & $0.98(0.50-1.93)$ & 2.54 & 0.28 & 21 & 0.1 \\
\hline CABG & $12-30$ - months & 2 & 529 & $44 / 438$ & 10.05 & 33329 & 4.40 & $1.40(0.44-4.40)$ & 0.06 & 0.8 & 0 & 0 \\
\hline $\begin{array}{l}\text { Vascular } \\
\text { Complications }\end{array}$ & 24 - months & 3 & 29619 & $1076 / 26312$ & 4.09 & $156 / 3307$ & 4.72 & $1.04(0.54-2.02)$ & 2.66 & 0.25 & 25 & 0.14 \\
\hline
\end{tabular}


a)

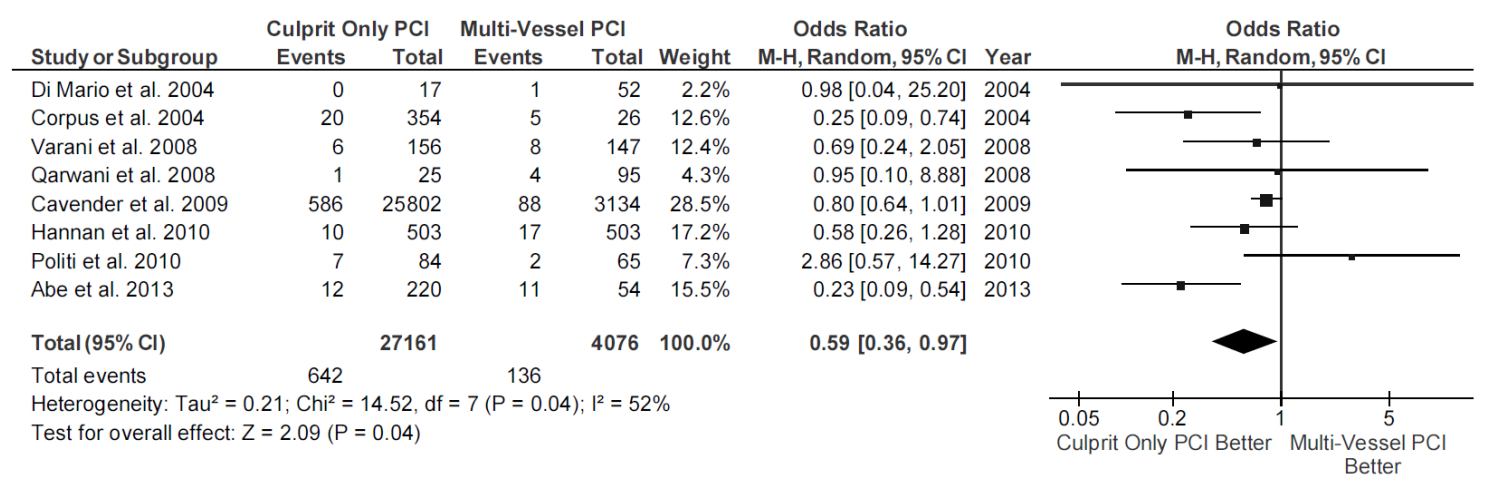

b)

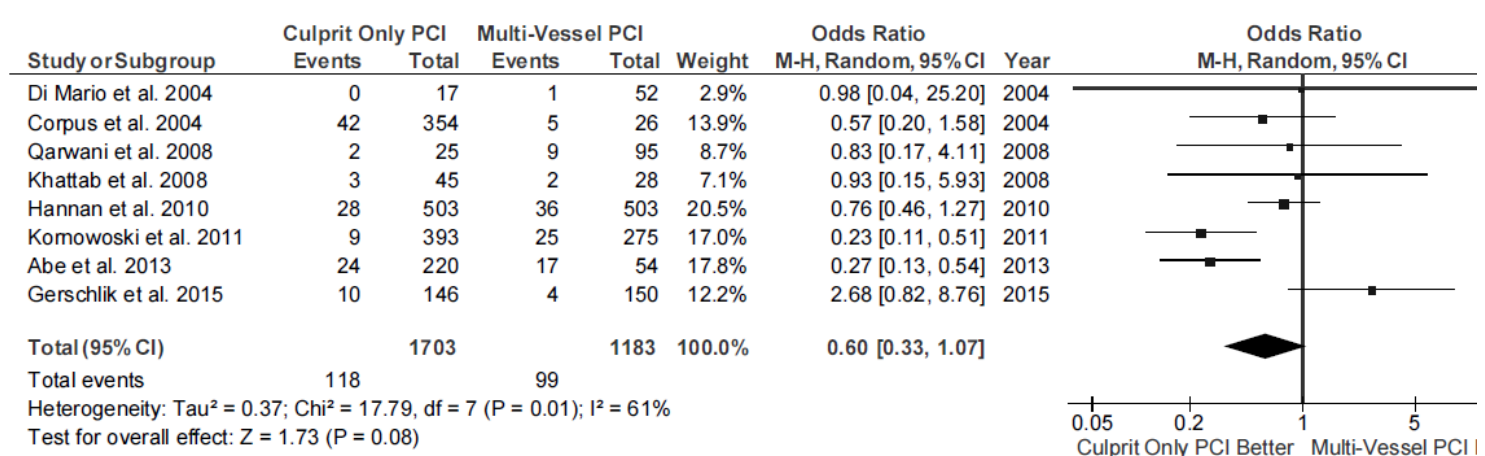

Figure 2. All-Cause Mortality (a) All-Cause Mortality (In-Hospital)._Culprit only is associated with lower all cause in-hospital mortality compared to multivessel PCI for STEMI. (b) AllCause Mortality (12 Months)._Culprit only and multivessel PCI were associated with similar all-cause mortality at 12 months.

a)

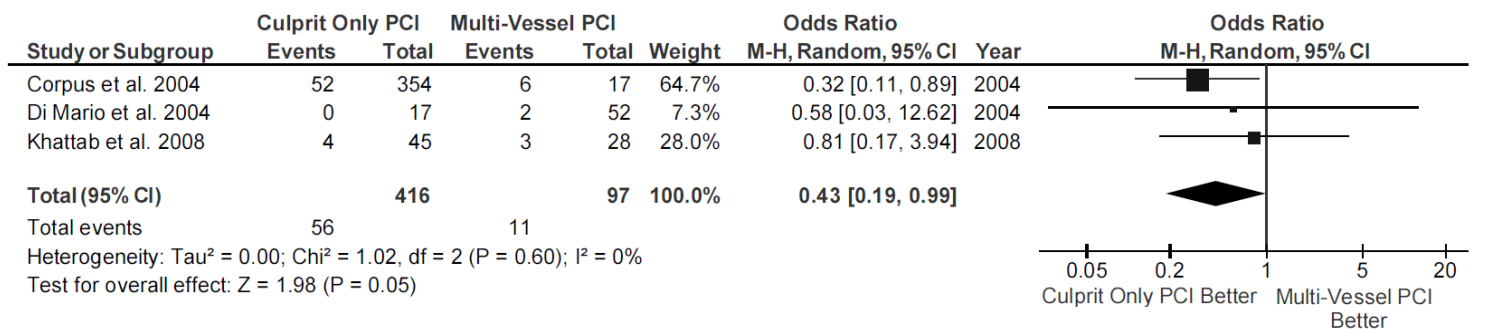

b)

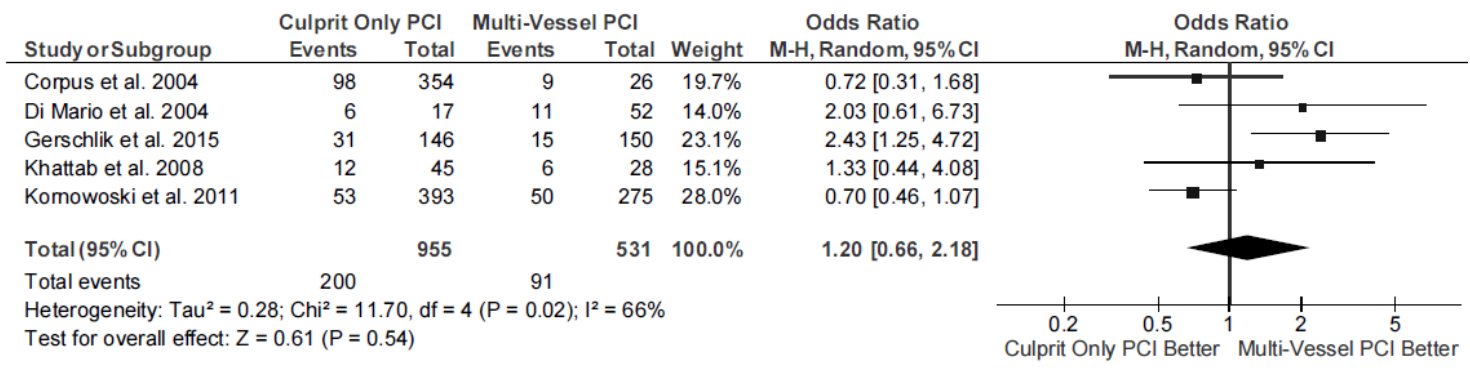

Figure 3. MACE 3(a) MACE (Short Term, 30-Day or In-Hospital). Culprit only was associated with lower short term (30 day or in-hospital) MACE compared to multivessel. (b) MACE (12 Months). Culprit only and multi-vessel were associated with similar rate of MACE at 12 months. 


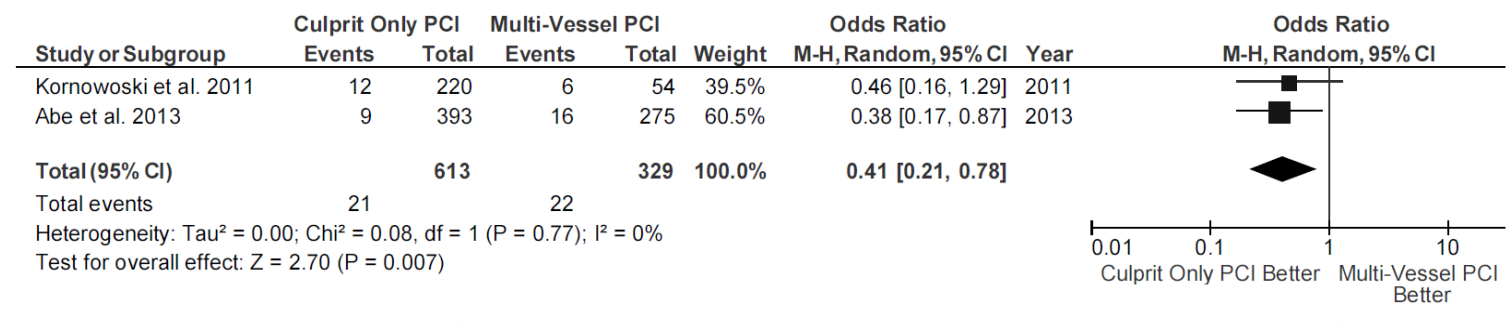

Figure 4. Stent Thrombosis (12 Months). Culprit only was associated with lower stent thrombosis at 12 months compared to multivessel PCI for STEMI.

\begin{tabular}{|c|c|c|c|c|c|c|c|c|}
\hline Study or Subgroup & \multicolumn{2}{|c|}{ Culprit Only PCI } & $\begin{array}{c}\text { Multi-Vess } \\
\text { Events }\end{array}$ & $\begin{array}{l}\text { I PCl } \\
\text { Total }\end{array}$ & Weight & $\begin{array}{c}\text { Odds Ratio } \\
\text { M-H, Random, } 95 \% \mathrm{Cl}\end{array}$ & \multicolumn{2}{|c|}{$\begin{array}{c}\text { Odds Ratio } \\
\text { M- } \mathrm{H}, \text { Random, } 95 \% \mathrm{Cl}\end{array}$} \\
\hline Gerschlik et al. 2015 & 7 & 146 & 2 & 150 & $21.9 \%$ & $3.73[0.76,18.25]$ & & \\
\hline Politi et al. 2010 & 10 & 84 & 4 & 65 & $37.9 \%$ & $2.06[0.62,6.90]$ & & \\
\hline Wald et al. 2013 & 10 & 231 & 4 & 234 & $40.1 \%$ & $2.60[0.80,8.42]$ & & \\
\hline Total $(95 \% \mathrm{Cl})$ & & 461 & & 449 & $100.0 \%$ & $2.58[1.22,5.42]$ & & \\
\hline Total events & 27 & & 10 & & & & & \\
\hline $\begin{array}{l}\text { Heterogeneity: } \mathrm{Tau}^{2}= \\
\text { Test for overall effect: }\end{array}$ & $\begin{array}{l}00 ; \mathrm{Chi}^{2}=\mathrm{C} \\
=2.49(\mathrm{P}=\end{array}$ & $\begin{array}{l}34, \mathrm{df}= \\
.01)\end{array}$ & $2(P=0.84$ & $\left.\right|^{2}=0 \%$ & & & $\begin{array}{ccc}0.05 & 0.2 & 1 \\
\text { Culprit } & 1\end{array}$ & $\begin{array}{cc}5 & 20 \\
\text { Multi-Vessel PCI Better }\end{array}$ \\
\hline
\end{tabular}

Figure 5. Cardiac Death (12 -30 months). Multivessel PCI was associated with a lower rate of cardiac death at 23-36 months compared to culprit only PCI.

a)

\begin{tabular}{|c|c|c|c|c|c|c|c|c|c|}
\hline \multirow[b]{2}{*}{ Study or Subgroup } & \multicolumn{2}{|c|}{ Culprit Only PCI } & \multicolumn{2}{|c|}{ Multi-Vessel PCI } & \multicolumn{3}{|c|}{ Odds Ratio } & & \multirow{2}{*}{$\begin{array}{c}\text { Odds Ratio } \\
\text { M-H, Random, } 95 \% \mathrm{Cl}\end{array}$} \\
\hline & Events & Total & Events & Total & Weight & $\mathrm{M}-\mathrm{H}$, Random, $95 \% \mathrm{Cl}$ & Year & & \\
\hline Corpus et al. 2004 & 53 & 354 & 3 & 26 & $9.1 \%$ & $1.35[0.39,4.66]$ & 2004 & & \\
\hline Khattab et al. 2008 & 9 & 45 & 5 & 28 & $9.5 \%$ & $1.15[0.34,3.86]$ & 2008 & & \\
\hline Komowoski et al. 2011 & 32 & 393 & 24 & 275 & $45.5 \%$ & $0.93[0.53,1.61]$ & 2011 & & \\
\hline Abe et al. 2013 & 31 & 220 & 7 & 54 & $18.0 \%$ & $1.10[0.46,2.66]$ & 2013 & & $=$ \\
\hline Gerschlik et al. 2015 & 16 & 146 & 8 & 150 & $17.9 \%$ & $2.18[0.90,5.27]$ & 2015 & & \\
\hline Total $(95 \% \mathrm{Cl})$ & & 1158 & & 533 & $100.0 \%$ & $1.18[0.81,1.71]$ & & & \\
\hline Total events & 141 & & 47 & & & & & & \\
\hline $\begin{array}{l}\text { Heterogeneity: } \mathrm{Tau}^{2}=0 \\
\text { Test for overall effect: } Z\end{array}$ & $\begin{array}{l}0 ; \mathrm{Chi}^{2}=2 . \\
0.86(P=0\end{array}$ & $\begin{array}{l}\text {, df }=4 \\
9 \text { ) }\end{array}$ & $(P=0.61)$ & $=0 \%$ & & & & 0.2 & $\begin{array}{lll}0.5 & 1 & 2\end{array}$ \\
\hline
\end{tabular}

b)

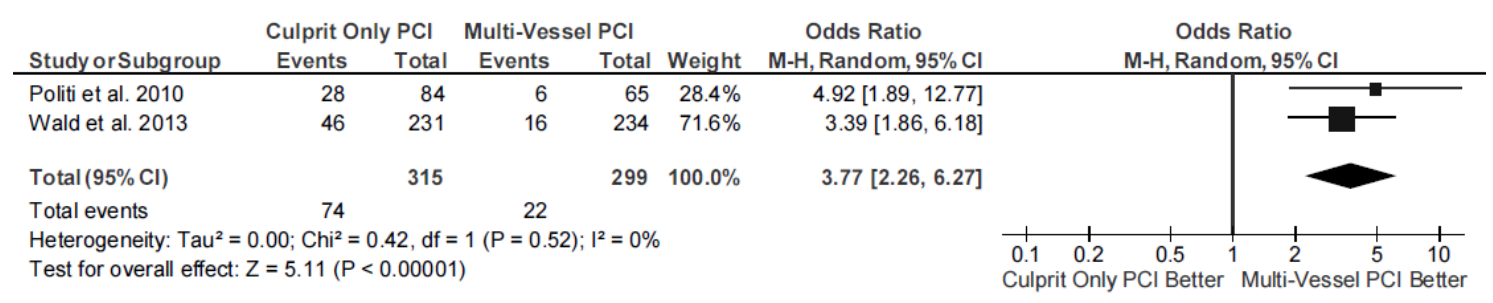

Figure 6. Revascularization (a) Target Vessel Revascularization (12 months). Culprit only and multivessel PCI were associated with similar target vessel revascularization at 12 months. (b). Total Repeat Revascularization ( 2 - 2.5 years). Multivessel PCI was associated a lower rate of repeat revascularization at longer term follow-up (23-36 months) than culprit only PCI.

The two groups had comparable rates of non-fatal MI, nonfatal stroke, target vessel revascularization, and major bleeding at 12 months follow-up (Table 3). Similarly, rates of CABG and vascular complications at 12-30 months follow-up were not significantly different between groups (Figures 7a, 7b).

\section{Discussion}

In our meta-analysis of 12 studies and 32,548 patients we found that culprit only PCI compared to multivessel PCI in the setting of STEMI was associated with a significantly lower incidence of in-hospital allcause mortality and 30-day MACE events. However, overall mortality and MACE did not differ significantly at 12 months and beyond. The mitigation of the positive outcomes at 30 days was largely driven by a higher incidence of repeat revascularization in the culprit only PCI group at $2-2.5$ years. Interestingly, multivessel PCI was associated with a lower isolated risk of cardiac death at 12-30 months and a higher rate of stent thrombosis at 12 months. The longer procedural time and greater number of stents deployed may worsen short-term outcomes with multivessel PCI, but improvement in outcomes at later followup intervals may be due to more complete revascularization. Complete revascularization when compared to incomplete revascularization in the setting of both CABG and PCI, is associated with improved mortality, decreased revascularization, and a lower rate of reinfarction [6].

Significant coronary stenosis in multiple arteries is seen in 40 $65 \%$ of patients undergoing primary PCI for STEMI and leads to significantly worse outcomes [7]. The 2013 ACCF/AHA guidelines for 
a)

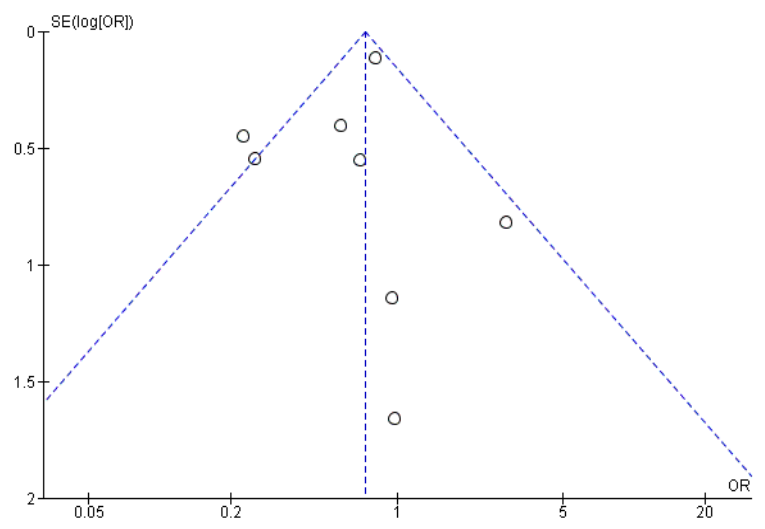

b)

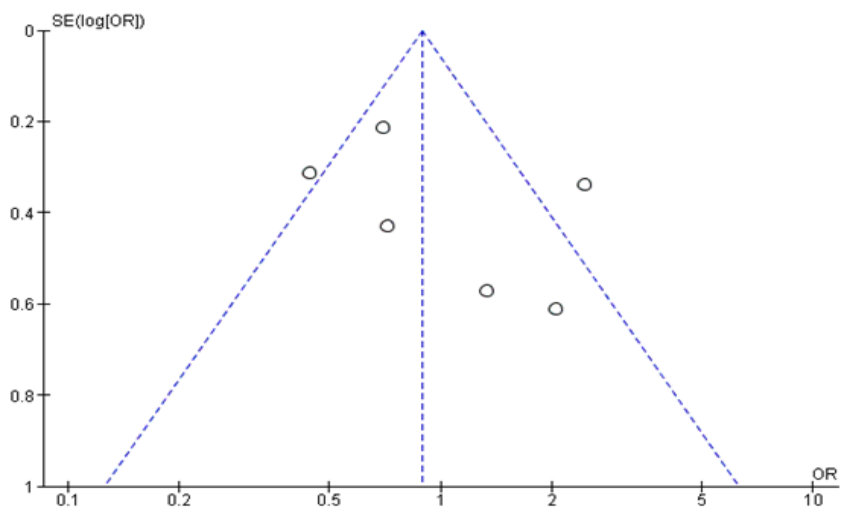

Figure 7. Funnel Plots (a) All Cause Mortality (Inhospital). (b) MACE (12 Months). a-b. We are comparing the odds ratio ( $\mathrm{x}$ axis) of individual studies to standard error of odds ratio (y-axis) on logarithmic scale. Visual inspection shows the studies are evenly distributed around no effect line, thus favoring lack of selection bias.

management of patients with STEMI acknowledged the variability in the evaluation and management of non-culprit coronary artery disease in hemodynamically stable patients with STEMI [1]. However, the 2012 appropriate use criteria for coronary revascularization deemed revascularization of a non-culprit artery during index hospitalization as inappropriate [7]. Both ACCF/AHA and ESC/EACTS guidelines have reiterated the need for additional evidence to clarify the indications for and timing of non-infarct artery revascularization [1,2]. Indeed, the results of two randomized controlled trials have since become available on the subject.

Existing studies have shown mixed results with some favoring culprit only and other favoring multivessel PCI. The studies have been limited either by observational design and the consequent selection bias [5,8-13] or a small sample size [14-17] with inadequate power to demonstrate a significant difference in hard end points like mortality or recurrent myocardial infarction. Both, culprit only and multivessel revascularization have their set of advantages and pitfalls. With a complete multivessel revascularization approach, an improvement in blood flow to the peri-infarct myocardium and stabilization of unstable, non-culprit plaques, seen in greater than $1 / 3^{\text {rd }}$ of patients with STEMI, can be achieved. Moreover, there is data from smaller studies indicating a significant improvement in ejection fraction with an initial multivessel PCI approach [18]. However, multivessel PCI has longer procedural time, higher risk for contrast induced nephropathy, and possibility of failed revascularization of non-culprit arteries. Furthermore, our meta-analysis found a higher rate of stent thrombosis in the multivessel group, likely related to the higher number of deployed stents. However, this was based on two 2 studies with limited events and therefore this finding may lack statistical power. Our metaanalysis helps put the findings of these important trials in perspective by addressing the limitations in these important outcomes.

This meta-analysis has a few limitations. First, as in all metaanalysis, publication bias associated with individual studies is inevitably inherent. Second, the included studies differed in inclusion/exclusion criteria or in the duration of follow-up. To minimize heterogeneity we only included studies where drug eluting stents were used and applied a random-effects model to account for inherent heterogeneity in the data. In addition, various outcomes were only pooled when available at pre-defined follow-up periods. Third, although a significant reduction in cardiovascular mortality is seen in our results, a limited number of studies (4 with a total of 979 patients) provided this outcome. Lastly, there was limited data on secondary outcomes such as stent thrombosis, major bleeding, contrast volume and vascular complications. Therefore the reduction in cardiovascular mortality and stent thrombosis as seen in our study is best considered hypothesis generating at this point. Enrollment in the Complete Versus Culprit-Only Revascularization to Treat Multivessel Disease After Primary PCI for STEMI (COMPLETE) trial is underway, which is expected to enroll 3,900 patients and is expected to be powered for outcomes such as long term myocardial infarction and cardiovascular mortality [18].

In conclusion, this meta-analysis demonstrated lower in-hospital all-cause mortality and 30-day MACE events and higher repeat revascularization with culprit only PCI. However, multi-vessel PCI during the index procedure was associated with a lower risk of cardiac death at 12-30 months. Either approach is however safe as evidenced by comparable rates of all cause death, MI, stroke, MACE events, major bleeding or vascular complications at 12 months follow-up. A significant reduction in repeat revascularization and cardiac at later follow-up was seen in patients who underwent multivessel revascularization.

\section{References}

1. O'Gara PT, Kushner FG, Ascheim DD, Casey DE Jr, Chung MK, et al. (2013) ACCF/ AHA Guideline for the Management of ST-Elevation Myocardial Infarction: A Report of the American College of Cardiology Foundation/American Heart Association Task Force on Practice Guidelines. J Am Coll Cardiol 61: e78-e140.

2. Kolh P, Windecker S, Alfonso F, Collet JP, Cremer J, et al. (2014) ESC/EACTS Guidelines on myocardial revascularization The Task Force on Myocardial Revascularization of the European Society of Cardiology (ESC) and the European Association for Cardio-Thoracic Surgery (EACTS) Developed with the special contribution of the European Association of Percutaneous Cardiovascular Interventions (EAPCI). Eur Heart J 35: 2541-2619.

3. Wald DS, Morris JK, Wald NJ, Chase AJ, Edwards RJ, et al. (2013) Randomized trial of preventive angioplasty in myocardial infarction. $N$ Engl $J$ Med 369: 1115-1123. [crossref]

4. Gershlick AH, Khan JN, Kelly DJ, Greenwood JP, Sasikaran T, et al. (2015) Randomized trial of complete versus lesion-only revascularization in patients undergoing primary percutaneous coronary intervention for STEMI and multivessel disease: the CvLPRIT trial. J Am Coll Cardiol 65: 963-972. [crossref]

5. Toma M, Buller CE, Westerhout CM, Fu Y, O'Neill WW, et al. (2010) Non-culprit coronary artery percutaneous coronary intervention during acute ST-segment elevation myocardial infarction: insights from the APEX-AMI trial. Eur Heart J 31: 1701-1707. [crossref] 
6. Garcia S, Sandoval Y, Roukoz H, Adabag S, Canoniero M, et al. (2013) Outcomes after complete versus incomplete revascularization of patients with multivessel coronary artery disease: a meta-analysis of 89,883 patients enrolled in randomized clinical trials and observational studies. J Am Coll Cardiol 62: 1421-1431. [crossref]

7. Patel MR, Dehmer GJ, Hirshfeld JW, Smith PK, Spertus JA (2012) ACCF/SCAI/ STS/AATS/AHA/ASNC/HFSA/SCCT 2012 Appropriate use criteria for coronary revascularization focused update: a report of the American College of Cardiology Foundation Appropriate Use Criteria Task Force, Society for Cardiovascular Angiography and Interventions, Society of Thoracic Surgeons, American Association for Thoracic Surgery, American Heart Association, American Society of Nuclear Cardiology, and the Society of Cardiovascular Computed Tomography. J Am Coll Cardiol 59: 857-881.

8. Abe D, Sato A, Hoshi T, Takeyasu N, Misaki M, et al. (2014) Initial culprit-only versus initial multivessel percutaneous coronary intervention in patients with ST-segment elevation myocardial infarction: results from the Ibaraki Cardiovascular Assessment Study registry. Heart vessels 29:171-177. [crossref]

9. Cavender MA, Milford-Beland S, Roe MT, Peterson ED, Weintraub WS, et al. (2009) Prevalence, predictors, and in-hospital outcomes of non-infarct artery intervention during primary percutaneous coronary intervention for ST-segment elevation myocardial infarction (from the National Cardiovascular Data Registry). Am J Cardiol 104: 507-513. [crossref]

10. Corpus RA, House JA, Marso SP, Grantham JA, Huber KC Jr, et al (2004) Multivessel percutaneous coronary intervention in patients with multivessel disease and acute myocardial infarction. Am Heart $J$ 148: 493-500. [crossref]

11. Khattab AA, Abdel-Wahab M, Röther C, Liska B, Toelg R, et al. (2008) Multi-vessel stenting during primary percutaneous coronary intervention for acute myocardial infarction. Clin Res Cardiol 97: 32-38. [crossref]

12. Kornowski R, Mehran R, Dangas G, Nikolsky E, Assali A, et al. (2011) Prognostic impact of staged versus "one-time" multivessel percutaneous intervention in acute myocardial infarction: analysis from the HORIZONS-AMI (harmonizing outcomes with revascularization and stents in acute myocardial infarction) trial. $J$ Am Coll Cardiol 58: 704-711. [crossref]

13. Qarawani D, Nahir M, Abboud M, Hazanov Y, Hasin Y (2008) Culprit only versus complete coronary revascularization during primary PCI. Int J Cardiol 123: 288-292. [crossref]

14. Di Mario C, Mara S, Flavio A, Imad S, Antonio M, et al. (2004) Single vs multivessel treatment during primary angioplasty: results of the multicentre randomised HEpacoat ${ }^{\mathrm{TM}}$ for cuLPrit or multivessel stenting for Acute Myocardial Infarction (HELP AMI) Study. Int J Cardiovasc Intervent 6: 128-133. [crossref]

15. Hannan EL, Samadashvili Z, Walford G, Holmes DR Jr, Jacobs AK, et al. (2010) Culprit vessel percutaneous coronary intervention versus multivessel and staged percutaneous coronary intervention for ST-segment elevation myocardial infarction patients with multivessel disease. JACC Cardiovasc Interv 3: 22-31. [crossref]

16. Politi L, Soura F, Rossi R, Monopoli D, Guerri E, et al. (2010) A randomised trial of target-vessel versus multi-vessel revascularisation in ST-elevation myocardial infarction: major adverse cardiac events during long-term follow-up. Heart 96: 662667. [crossref]

17. Varani E, Balducelli M, Aquilina M, Vecchi G, Hussien MN, et al. (2008) Single or multivessel percutaneous coronary intervention in ST-elevation myocardial infarction patients. Catheter Cardiovasc Interv 72: 927-933. [crossref]

18. Ochala A, Smolka GA, Wojakowski W, Dudek D, Dziewierz A, et al. (2004) The function of the left ventricle after complete multivessel one-stage percutaneous coronary intervention in patients with acute myocardial infarction. J Invasive Cardiol 16: 699-702. [crossref]

19. Complete vs Culprit-only Revascularization to Treat Multi-vessel Disease After Primary PCI for STEMI (COMPLETE). Clinical trials.gov. https://clinicaltrials.gov/ ct2/show/NCT01740479 [Accessed on 22 May 2015].

Copyright: (C2016 Wong D. This is an open-access article distributed under the terms of the Creative Commons Attribution License, which permits unrestricted use, distribution, and reproduction in any medium, provided the original author and source are credited. 